\title{
A Way of Comparing Lévi-Strauss and Lacan
}

Yvan Simonis

Anthropologist and Psychoanalyst (GIFRIC)

This essay attempts to compare and contrast the different conceptions of the human subject in Claude Lévi-Strauss and Jacques Lacan, with specific reference to the notions of art and the act. For this occasion I will draw on my reading of structuralism, developed elsewhere, as a "logic of the aesthetic perception of the social." Structuralism apparently distances itself from the act, but it presupposes the act as a foundation. Psychoanalysis takes the act as its point of departure and seeks its art. In each case, the human subject is conceived differently. Nonetheless, the exercise appended to this essay proposes a space in which these two approaches can perhaps encounter each other on the common ground of structure.

Writing about Claude Lévi-Strauss to open a debate with Lacan about art, the act, the subject, the unconscious, and language-nothing less-is of course risky. While proposing some crucial differences between structuralism and Lacanian psychoanalysis concerning these several concepts, I am indeed afraid to reduce structuralism to a caricature that will be too easy to criticize.

This short paper is certainly far too condensed to do justice to the magisterial work of Lévi-Strauss solely by submitting it to the critique of psychoanalysis. Neither of these two approaches to the human phenomenon can assimilate the other one. Yet they overlap on a few points without really being in agreement. As you will see, I propose to situate the main differences between Lévi-Strauss and Lacan around their ideas about art and the act. For Lévi-Strauss I would say that structuralism is the art of supposing the work of the act by distancing oneself from it, and for Lacan I would say that he turns around the acts of the Real, which reveal where the subject stands and looks to produce his own work of art.

I. Lévi-Strauss often hesitated. He was aware that acts of human intervention produce the raw material for structuralist analysis-things like social organization, kinship, rituals, myths, techniques, etc.- - but he thought that these products kept in them the trace of something that escaped the consciousness of their authors, and that this something was located at a level that ties all these products to one another. Drawing inspiration from the works of Roman Jakobson and Ferdinand de Saussure, Lévi-Strauss argued that all social products are marked by the symbolic organization that is characteristic of human languages. 
These linguists tell us that language implies an unconscious articulation of phonemes that are distinguishable by distinctive features, and form between them a system that is a necessary condition for speaking meaningfully — and therefore for acting meaningfully. They add that we are by no means the authors of this system. Lévi-Strauss starts from the hypothesis that all human productions also carry a systematic level of articulation that escapes them by remaining unconscious. Retrieving the traces of this unconscious articulation in all human productions becomes the only real interest of structuralism. This is why Lévi-Strauss jumped from kinship to rituals and later from myths to music, yet moved further and further away from acts in order to emphasize their conditions of possibility and their dependency.

When so examined, myths turn out actually to be extremely inventive explorations-of nature, the body, events, social rules, feelings, good and evil, or anything that is human or natural. Myths use a number of encodings to make everything meaningful in the construction of their stories. Here structuralism acts like an actor who reads the logic implied by the work of myths that "think themselves" through him. The ways in which these myths are rooted socially, politically, economically, and philosophically, or culturally, locally, and in the family, are only relevant as accidents, supposing acts, that trigger the inner work of mythical logic.

As Lévi-Strauss sees it, mythical thinking expresses clearly but by a paradoxical detour his secret hope to reveal the framework of the logic that sustains and defines the real. Why is this detour paradoxical? On the one hand, the imagination seen in myths may appear delirious, but it turns out to be even more regulated than any human production by the constant work of a logic of differences that deploys, beyond the mythical imaginary, the prodigious diversity of codes in which the activities of the mind are inscribed.

Lévi-Strauss counts on events that have become inscribed in the form of a work-an “œuvre." He does not underestimate the importance of acts for thinking. Indeed, there is no structural analysis without the work of events-accidents.

As he says: "In so far as early art, primitive art and the 'primitive' periods of professional painting are the only ones which do not date, they owe it to this dedication of the accidental to the service of execution and so to the use, which they try to make 
complete, of the raw datum as the empirical material of something meaningful." (The Savage Mind 29)

By what may seem like a long detour, the structural analysis of myths often sheds light on history by going back to it with new hypotheses on how past acts inscribed in various encodings testify to the vigor of conflicts and exchanges between neighboring peoples whose myths and differential development structuralism studies. Experience and the thinking that develops through it are coded in multiple ways and suppose the work of number of previous acts.

Encodings use a large number of natural (sun, moon, stars, animal behaviors, diverse forms of objects of any sort, etc.) or social forms (habitats, customs, rites, etc.) that the mind does not invent but that give the mind material for coding and thinking. These are not limited to the sexual code. For Lévi-Strauss, the sexual code was insufficient for reading the variety of consequences produced by the acts-events of even the Oedipus myth. This is why he criticized Freud's reading of that myth in Totem and Taboo.

Structuralism has a sense of temporal depth. It openly admits that structural analysis presupposes acts, events, or ancient accidents. "In the end," said Lévi-Strauss in I97I, "if the customs of neighboring peoples display a symmetrical relation, one should not only seek the reason for this in some mysterious law of nature or the mind. This geometrical perfection also sums up, in the present mode, more or less conscious but countless efforts accumulated by history. .." (1973: 300).

Lévi-Strauss thus grounds human activities (kinship, the economy, politics, art, and all the events that he calls accidents) in various encodings that transmit to one another the function of finding meaning. Little by little, this work reveals that these coded inscriptions fix humans in the symbolic, conceived as the various parts of the possible logics regulated by the mind that keeps in unconscious reserve all the possible parts. Little by little, this reduction operates, and will verify that what we believe is unique to humans actually reveals our anchoring in the materiality of the universe.

Curiously, Lévi-Strauss uses the metaphor of art and artistic activity to explain the relevance of the structuralist project. In Entretiens avec Claude Lévi-Strauss (1961), George Charbonnier asks Lévi-Strauss: “For you, is the artist someone who aspires to language?" LéviStrauss responds as follows: 
$\mathrm{He}$ is someone who aspires the object into language, if you allow me this formulation. He faces an object, and in the face of this object, there is really an extraction, an aspiration, that turns this object, which used to be a being of nature, into a being of culture. And it is in this sense that, as I was saying earlier, the classic phenomenon in which ethnologists are interested, namely the passage from nature to culture, finds in art a privileged manifestation. (I3I)

But this is not only about the passage from nature to culture. For Lévi-Strauss, what teaching does this passage contain? In response to a reaction by Charbonnier reminding him that the artist also wants to leave culture to move toward nature, Lévi-Strauss says this:

This is not contradictory, insofar as the promotion of an object into a sign, if it succeeds, must bring to light some fundamental properties that are common both to the sign and to the object, a structure which is manifest in the sign and which is normally hidden in the object, but which, thanks to the plastic or poetic representation of that object, appears suddenly, and incidentally allows the passage to all sorts of objects. There is a double movement which, through the medium of this linguistic experience, allows to discover or to notice some normally hidden features of the object, and these are the very features that the object shares in common with the structure and the mode of functioning of the human mind. (|3|-32)

Let's add the two lines that immediately follow: Charbonnier: "I believe we can say that there is art only on the condition that the second movement is implemented."

Lévi-Strauss: “Certainly.”

This aspiration of nature toward culture leads, as we can see, to the paradoxical discovery of a commonality of the mind with the object. In the innermost being of either one of them, something structural triumphs, of which language is the finest expression, and that objects also express when they are "speaking." 
When one considers the work of art as the product of an activity that renounces sensible aspects by acquiring intelligible dimensions, and as a choice among solutions that could have taken a different face, the solution that was eventually adopted also reveals as a watermark those that were rejected. Here I quote Lévi-Strauss again:

The choice of a solution involves a modification of the result to which another solution would have led, and the observer is in effect presented with the general picture of these permutations at the same time as the particular solution offered. He is thereby transformed into an active participant without even being aware of it. (The Savage Mind 24)

II. The structuralism of Lévi-Strauss takes us, as we can see, in a direction that moves us away from Lacanian perspectives.

Lévi-Strauss and psychoanalysis agree about the importance of signifiers. Both are suspicious of consciousness and the self. Lévi-Strauss once said, "Whoever starts to settle in the supposedly obvious facts of the self will not come out of it" (La Pensée Sauvage 329). Psychoanalysis has no trouble adopting this perspective, but fundamentally differs from structuralism as soon as it discusses the subject, desire, or the acts of the Real.

Both speak about the unconscious, about what escapes us and grounds us, but the fundamental differences quickly appear.

Psychoanalysis goes toward a Real that inscribes itself, a Real that is located beyond the symbolic. Structuralism stays on the side of language, whose model it considers unsurpassable. There are also differences between Lévi-Strauss and psychoanalysis concerning what remains unconscious. For structuralism, what escapes us and remains unconscious is the human mind and all its possibilities. For psychoanalysis, what remains unconscious is what cannot be represented, what is not of the order of fantasy. These two perspectives are oriented in opposite directions. They intersect, but their journey irremediably takes them away from each other.

Under the impact of the linguistic model used by Lévi-Strauss, Lacan had endorsed the priority of signifiers organized in structures. He had thus moved away from the unconscious associated with the repressed to situate it progressively as a translation of a chain of signifiers. Later, Lacan put at the center of his approach the concepts of Enjoyment 
(la Jouissance) and the Real, of béance ("gap," “chasm”) and suture ("stitching”). He thus moved from structure to knots that are no longer a matter for linguistic models.

"My saying--that the unconscious is structured like a language--is not of the realm of linguistics." Lacan had specified (cited by Toboul 316). Lacan had also humorously proposed to call "linguistry" the knowledge about language that psychonanalysis carves (3/7).

In Structural Anthropology, Lacan had noticed Lévi-Strauss's early famous texts ("The Sorcerer and his Magic" and "The Effectiveness of Symbols"), which were at the root of later debates in psychoanalysis. There, Lacan had found the "structuralist definition" of magic: "it supposes that signifiers respond as such to signifiers. The signifier of nature is called by the signifier of incantation. It is "metaphorically mobilized." As Annie Tardits comments in Drach et Toboul, "the discreetly provocative point consists in bringing this 'bridge of correspondences'-which is implied by magic between these two locations of the signifier-closer to the correlation insistently highlighted by Lévi-Strauss between the classifications and combinations of thought-savage or not-and the architecture of molecules discovered by modern biology: a magical 'bridge of correspondences,' if there is any. ..." (209). This was going to pose problems. Marcel Drach writes,

This taking of distance is indicated, in the Seminar L'Angoisse in 1962, by the theme of béance. Thus is marked the impossible, the symbolization of which is limited by Lacan's Real, against the Enlightenment materialism professed by Lévi-Strauss, which puts the symbolic in continuity with empirical reality through the medium of brain structure. (Drach et Toboul I5)

Where is the subject in these matters?

For Lévi-Strauss, the subject is reduced to the symbolic function that forces and appropriates the subject when events take place.

For Lacan, the subject is referred to desire under the recurrent impact of the Real beneath the symbolic, the Real being the absent cause of the subject of desire.

Lévi-Strauss does not go beyond mental representations and has no room for a "lack to jouissance." He went no further than the equivalent of a degree zero on the side of the subject. To him, there is an unthinkable that explains affect, feelings - a leftover, but LéviStrauss is not interested in accounting for it. Subjectivity is reduced to the muddles of the 
self and its lived experience, a kind of flower produced by the work (which escapes the self) of the chance meeting of ancient geological layers whose maneuvers we do not control.

For Lévi-Strauss, comments Philippe Mengue in Drach et Toboul,

the empty slot is simply a passive formal condition that enables mutations, the transformations of a given order. For Lacan, on the contrary, the structure is structuring only from an active void that plays the role of a quasi-cause, an absent cause, in the structuring of the subject as a subject of desire. (228)

“Indeed," writes Toboul, "for Lévi-Strauss, the structure imposed the order of the oppositive difference that language constitutes. . . But the paradigm of enjoyment (jouissance) jostles the subtle balance between the lack (béance) and the structure. A new regime of difference finds its legitimacy" (Drach et Toboul 278). And, Toboul continues,

... the signifier no longer maintains itself as master of the game, and the subject of the unconscious comes to change names. To retrieve the radicality of Freud, all foundations are revoked, and to foundationlessness responds semblance. All the stabilities enabled by the Symbolic waver. It is the time of the Real; a new regime of difference needs to be produced that will not be that which structures language. The linguistic model exits the stage. (Drach et Toboul 279)

The Real of la Jouissance creates an asymmetry through an event that is not integrated into the established symmetries. Structuralism contains the art of supposing this kind of event, but only after it has brought about other symmetries, whereas psychoanalysis speaks of acts of the Real that require subjects to find their art.

The Real acts and the body is at stake in its inscriptions. We need to begin from the concrete, the sensible. Structuralism goes toward what it thinks is a logic of the sensible, a logic of forms that is fashioned without ever leaving the sensible, without going through abstraction, nor even through speech. For structuralism, meaning is on the side of silence and music.' 
Where the Real makes an act, one must go to the details, not to substitutive generalities. The Real has no desire, in my view, but it leads to desire, it imposes it, it reveals desire through acts that inform us that we are not confined by the dictates of mental representations and therefore of fantasies.

Don't forget the trauma which is implied by the work of the Real. "Thus trauma is the mark that the subject is not reducible to being represented," says Alain Vanier (Drach et Toboul 259).. Trauma is this strike by the Real that establishes the subject as a lack of Jouissance that is indicated by the object $a$.

The question that is asked when we say "The Real acts" is "Does it act out of nothing, ex nihilo?" Answering yes to this question would apparently reinforce the mystery, whereas answering no would imply that the Real is each person's Real and is inscribed for the subject.

The acts of the Real are already snapped up by desire. This, in my view, reveals that the subject desired these acts and that he suddenly faces the ethical choice of recognizing these acts as his own. Citing Lacan (200I:200)Toboul says, “. . . we notice that the being of the subject is the stitching (suture) of a lack" (304). As we can see, we are far from the unitary subject: "The subject re-breaches itself of being at once effect of the mark and support for its lack" (305). ". . . the subject is what responds to the mark by what the mark lacks" (Lacan 200I: 200).

The mark that we evoke here is like a scar, an inscription, the result of a reaction to a hallucination within the subject in a body that bears witness henceforth to the disorganization of the organic realm by the work of the letter, the precise point of the relation between the Symbolic and the Real around a void that the Symbolic ensures and therefore around a loss, a lack, which nourishes desire and the drive.

"The subject of the unconscious functions, then, like the paradoxical point by which the structure ensures its coherence, but upon an exclusion," writes Toboul (Drach et Toboul 278).

As we can see and as Claude-Noële Pickmann rightly reminds us (Drach et Toboul I07-I I4), the knotting together of what escapes and what accesses the signifier, of the unthinkable and the symbolic, and of the gap and meaning (semblance), does not serve to make a synthesis or a unitary totality. 


\section{Conclusion}

Psychoanalysis, it seems to me, is a science of the morning. It desires to understand how the beginnings of the subject and his inscription in the group are knotted together. It knows that these beginnings are always there, and that the beginnings of the subject are the very source of his artistic reactions, of the acts which do and undo him. This position indeed conveys quite another conception of the subject than the one proposed by structuralism.

Psychoanalysis strives to read the inscriptions of the Real on the body of the subject. But this doesn't mean that under the pretext of the reaction of the subject to these inscriptions we should not pay attention to the encounters between fantasies and the body. Here, Lévi-Strauss should teach us something by drawing our attention toward other locations of these inscriptions.

Structuralism, on the other hand, is a science of the evening. It is interested in the ancient outcomes of the history of these subjects. For structuralism, the accumulated inscriptions of this activity reveal through the objects it has produced that humanity is irremediably inserted in materiality and that the mind is only the delegate of the things it gives voice to.

Lévi-Strauss is right to offer no privilege to the human species, which, as he said, "will disappear without leaving a trace on the scale of the planets," and he indefatigably tried to relate this species to a materiality that plays itself out through it.

But, as Richard Rechtman says with some humor, "structural logic supposes the emancipation of subjectivity" (Drach and Toboul 194). And indeed, structural logic owes nothing to each person's subjectivity.

At the end of this text, let me draw your attention to the following appendix. For those who know Lévi-Strauss and Lacan, I propose an exercise which is more proximate to what both authors mean when they talk about structure. In my view, one can immediately see the implications of their understanding of the notion of structure and then of the conceptions of the subject, art, and the act. 


\section{Appendix}

\section{Fx (a) : Fy (b) Fx (b) : Fa- I (y) ${ }^{2}$}

Let us try to use this famous formula by Lévi-Strauss that he always used to work and explain what he was doing - a formula bearing the logic of the Moebius strip or of a Klein's bottle. Its main logical feature is to trace the work of the inversion that has a closing effect and maintains the frame of the dynamic of a group of transformation. By way of illustration, let me itemize what the components of this formula would become in a psychoanalytical space:

(a) would be the self

(b) would be the body

“a - I" would be the unconscious

$x$ would be knowledge (savoir)

y would be desire

The formula would thus read as follows:

\section{The knowledge (fx) carried by the self (a) has the same type of relation with desire (fy) inscribed on the body (b) as knowledge (fx) inscribed on the body (b) does with what remains unconscious (fa- I) within desire (fy).}

We therefore need to ask what type of relation would be roughly similar on both sides of the formula.

I would say that the formula denotes a relation of dependency and therefore a hierarchical relation that is founded on a non-relation, that is, a gap, a hole, an irreducible ignorance. ... and the impossibility of reducing the subject to any single level.

We are here on the territory of Lacanian knots. It would probably be fruitful to try to re-write some Borromean knots with this formula. This is a ground for a possible discussion 
between structuralism and psychoanalysis, and perhaps this discussion would show that Levi-Straussian formulas did not exclude the work of béance.

Translated by Fabien Simonis ${ }^{3}$ 
' Marcel Drach (Drach et Toboul I70-7I) makes the interesting suggestion that we should remain attentive to what Lévi-Strauss says about music when he tries to valorize access to musical experience, starting with the babbling of infants, in which the boundary of phonemes and music is at stake through the establishment of signifying sounds, but for Lévi-Strauss music is not on the side of Lacan's language, otherwise he would have been interested in concrete music rather than abhorring it. For Levi-Strauss, music goes beyond the symbolic; it is the very example of the rediscovery of logic and the sensible; it is at once logic and sense-perception; it avoids all of the risks of the symbolic. Marcel Drach seems to tell us that that babbling of infants bears witness perhaps to a moment when one can still perceive the manner in which the positioning of logic and of the sensible dimension is established. But it seems to me that the babbling of infants, far from any apparent logic, is based rather on the confusion that Levi-Strauss criticizes in concrete, serial, and dodecaphonic music, all of which pretends to ground music in an aleatory logic, and distances itself from its anchoring in the experience of a sensible dimension inscribed in nature.

${ }^{2}$ This formula always inspired the work of Levi-Strauss from Anthropologie Structurale (1958 : 252 ) on. As he reminds those who would underestimate its importance in Du miel aux cendres : Mythologiques 2 (1966:212), “it has not ceased guiding us."

${ }^{3}$ I gratefully thank my son Fabien Simonis for taking charge of the translation of this text only a few days before I originally presented it at the seminar of GIFRIC in spring 20I0. I also gratefully thank Jeffrey Librett who believed this essay was of a potential interest for the readers of the journal he is in charge of, for pushing me to rework parts of the text. I am of course entirely responsible for what I have done, in this respect, within a very tight deadline.

\section{Works Cited}

Drach, Marcel and Bernard Toboul (eds.), L'anthropologie de Lévi-Strauss et la psychanalyse. Paris, La Découverte, 2008.

Anthropologie, Psychanalyse et État, Journal des Anthropologues. Paris, 2009, n I I6-I I7, Paris.

Lacan, Jacques. Autres écrits. Seuil: Paris, 2001.

Charbonnier, Georges. Entretiens avec Claude Lévi-Strauss. Plon et Julliard: Paris, 196I.

Lévi-Strauss, Claude. Anthropologie structurale. Plon : Paris, 1958.

---. La Pensée Sauvage. Plon: Paris, 1962.

---. The Savage Mind, Chicago University Press, 1966.

Lévi-Strauss, Claude. Du miel aux cendres. Mythologiques 2. Plon : Paris, 1966. 
---. Anthropologie structurale deux. Plon : Paris, 1973.

Simonis, Yvan. Claude Lévi-Strauss ou la «passion de l'inceste» Coll. Champs : Flammarion, Paris. 1980 (1967). 